\title{
Electrospun PLA: PCL composites embedded with unmodified and 3-aminopropyltriethoxysilane (ASP) modified halloysite nanotubes (HNT)
}

\author{
Hazim J. Haroosh ${ }^{a}$, Yu Dong ${ }^{\text {b, }}$, Deeptangshu S. Chaudhary ${ }^{\text {a }}$, Gordon D. Ingram ${ }^{\text {a }}$ \\ and Shin-ichi Yusa ${ }^{\mathrm{c}}$ \\ ${ }^{a}$ Department of Chemical Engineering, Curtin University, Perth, WA 6845, Australia \\ ${ }^{b}$ Department of Mechanical Engineering, Curtin University, Perth, WA 6845, Australia \\ ${ }^{c}$ Department of Materials Science and Chemistry, University of Hyogo, Himeji, Hyogo \\ 671-2280, Japan
}

\begin{abstract}
Electrospinning is a simple and versatile fiber synthesis technique in which a highvoltage electric field is applied to a stream of polymer melt or polymer solution, resulting in the formation of continuous micro/nanofibers. Halloysite nanotubes (HNT) have been found to achieve improved structural and mechanical properties when embedded into various polymer matrices. This research work focuses on blending poly( $\varepsilon$-caprolactone) (PCL) (9 wt \%/v and $15 \mathrm{wt} \% / \mathrm{v})$ and poly(lactic acid) (PLA) (fixed at $8 \mathrm{wt} \% / \mathrm{v}$ ) solutions with HNT at two different concentrations $1 \mathrm{wt} \% / \mathrm{v}$ and $2 \mathrm{wt} \% / \mathrm{v}$. Both unmodified HNT and HNT modified with 3-aminopropyltriethoxysilane (ASP) were utilized in this study. Fiber properties have been shown to be strongly related to the solution viscosity and electrical conductivity. The addition of HNT increased the solution viscosity, thus resulting in the production of uniform fibers. For both PCL concentrations, the average fiber diameter increased with the increasing of HNT concentration. The average fiber diameters with HNT-ASP were reduced considerably in comparison to those with

* Corresponding author. Tel.: +61 8 92669055; fax: +61 892662681.

E-mail address: Y.Dong@curtin.edu.au (Y. Dong).
\end{abstract}


unmodified HNT when using $15 \mathrm{wt} \% / \mathrm{v}$ PCL. Slightly better dispersion was obtained for PLA: PCL composites embedded with HNT-ASP compared to unmodified HNT. Furthermore, the addition of HNT-ASP to the polymeric blends resulted in a moderate decrease in the degree of crystallinity, as well as slight reductions of glass transition temperature of PCL, the crystallization temperature and melting temperature of PLA within composite materials. The infrared spectra of composites confirmed the successful embedding of HNT-ASP into PLA: PCL nanofibers relative to unmodified HNT due to the premodification using ASP to reduce the agglomeration behavior. This study provides a new material system that could be potentially used in drug delivery, and may facilitate good control of the drug release process.

Keywords: Electrospinning; Nanofibers; Halloysite nanotubes (HNT); Hybrid composites; Material characterization; Micro/nanostructures

\section{Introduction}

Electrospinning is a fabrication method that offers the efficient and economical manufacture of three-dimensional fibrous structures [1]. The electrospun fibers create a fabric network that has a high porosity, very small pore size, and very large surface-tovolume ratio [2, 3]. Therefore, they could be used for many biomedical applications, such as drug delivery, artificial organs, wound dressing, and medical prostheses $[4,5]$. Electrospinning is often greatly influenced by both material parameters such as solution viscosity, solution concentration, surface tension, and electrical conductivity, as well as processing factors including high voltage setting, feed rate of solution, collector type, and working distance. Among all these parameters, solution viscosity plays a key role in the 
fiber formation owing to its direct link with the number of entanglements of the polymeric chains [6].

Poly( $\varepsilon$-caprolactone) (PCL) is a semicrystalline polymer that is widely employed in tissue scaffolding due to its good drug permeability and slow biodegradability [7]. PCL is also commonly utilized in long-term implantable devices [8]. Poly(lactic acid) (PLA) is mostly used in various biomedical applications, benefiting from its biodegradability, good mechanical properties, and biocompatibility $[9,10]$. Halloysite nanotubes (HNT) are clays belonging to the kaolinite group. HNT with good biocompatibility [11] are tubular in shape and are 300-1500 $\mathrm{nm}$ in length, $40-120 \mathrm{~nm}$ in outer diameter, and 15$100 \mathrm{~nm}$ in inner diameter. It has been lately reported that the incorporation of HNT within a PLA polymer matrix can counteract the negative effects of the acidic degradation of PLA based products in the presence of hydroxide groups, as presented in the HNT structure [12].

This paper investigated the experimental characterization of electrospun PLA: PCL/HNT composites in a novel material system, which consists of high molecular weight PCL and 3-aminopropyltriethoxysilane (ASP) as a surface modifier to improve the embedding effect and homogeneous HNT dispersion within electrospun nanofibers. Such a PLA: PCL based composite system could help to achieve balanced crystallinity with the possible benefit of steady drug release, since PCL with high crystallinity easily restricts the mobility of drug molecules so they tend to stay on the fiber surfaces [13]. Besides, the addition of PLA with low crystallinity can accelerate fiber degradation. Two different PCL concentrations, namely 9 and $15 \mathrm{wt} \% / \mathrm{v}$, were chosen in this study in order to understand how the blend viscosity affects the nanofiber diameter and degree of 
crystallinity, which are regarded as two important factors in the control of drug release. The blend viscosity is in turn an important factor for HNT dispersion within the polymer blend in the electrospinning process. The current work has promoted nanofiber quality without any bead defects or nonfibrous structures by controlling the crystallinity level of PLA: PCL blend. Furthermore, HNT agglomeration was reduced by using the ASP modifier, which has direct benefits for future drug release applications.

\section{Materials and processing methods}

\subsection{Materials}

Poly(lactic acid) 3051D, molecular weight $(M W)=93,500 \mathrm{~g} / \mathrm{mol}$, glass transition temperature $T_{g}=65.50^{\circ} \mathrm{C}$ [14], was supplied by NatureWorks, USA. The halloysite

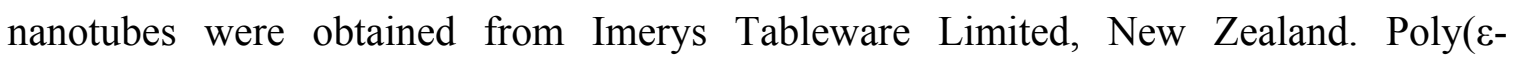
caprolactone) with $M W=80,000 \mathrm{~g} / \mathrm{mol}, 3$-aminopropyltriethoxysilane, and two solvents of chloroform and methanol were purchased from Sigma-Aldrich, Ltd. without any purification.

\subsection{Electrospinning}

Electrospinning was carried out using $8 \mathrm{wt} \% / \mathrm{v}$ solution of PLA mixed with either a 9 $\mathrm{wt} \% / \mathrm{v}$ or $15 \mathrm{wt} \% / \mathrm{v}$ solution of PCL. The PLA and PCL solutions were both mixed at a 1:1 volume ratio. The solvents used in all cases were chloroform and methanol blended in a 2:1 volume ratio.

In order to modify HNT by using ASP, $2 \mathrm{~mL}$ of ASP was initially dissolved in $30 \mathrm{~mL}$ of chloroform/methanol. About $2 \mathrm{~g}$ of HNT powder was added to the ASP solution and the suspension was sonicated for $1 \mathrm{~h}$ at room temperature. The suspension was then 
heated at $120^{\circ} \mathrm{C}$ for 6 to $8 \mathrm{~h}$ by using a magnetic stirrer attached to a hot plate. The deposited HNT-ASP in the resulting mixture was filtered and thoroughly washed twice with chloroform/methanol, and then dried for $24 \mathrm{~h}$ at $120^{\circ} \mathrm{C}$ to ensure the removal of all solvents. Meanwhile, the unmodified HNT were sonicated separately in the chloroform/methanol solvents for $1 \mathrm{~h}$ and the suspension was then heated and dried using the same method as for the modified HNT. $1 \mathrm{wt} \% / \mathrm{v}$ and $2 \mathrm{wt} \% / \mathrm{v}$ of HNT were added to the blended polymer solution and were mixed for an additional $2 \mathrm{~h}$. During the electrospinning process, the solutions were ejected using a $10 \mathrm{ml}$ syringe pump with a $20 \mathrm{G}$ metallic needle $(0.584 \mathrm{~mm}$ inner diameter). The flow rate of polymer solution was 2 $\mathrm{ml} / \mathrm{h}$, and the applied positive voltage setting was in the range of $25-28 \mathrm{kV}$. The electrospinning process was carried out at $24^{\circ} \mathrm{C}$. The resulting fibers were collected on a flat aluminum foil sheet covering a mesh collector. The distance between the needle tip and the collector was $13 \mathrm{~cm}$. The thickness of fiber mats ranged from 310 to $470 \mu \mathrm{m}$.

\subsection{Characterization techniques}

Solution viscosity was measured by using a Visco 88 portable viscometer from Malvern Instruments (UK), which has a built-in temperature sensor and a double gap measuring set-up to provide extra sensitivity for low-viscosity fluids. The morphology of the electrospun nanofibers was studied via an EVO 40XVP scanning electron microscope (SEM) at an accelerating voltage of $5 \mathrm{kV}$. Before SEM observation, the samples were sputter-coated with platinum. Fiber diameter was calculated from the SEM images by using an image analysis tool in the Zeiss Smart $\mathrm{SEM}^{\circledR}$ software. For each sample, diameter measurements were made based on at least 150 fibers from multiple scanned SEM images (approximately 15 fibers per image). 
The nanofiber matrix was embedded in Araldite ${ }^{\circledR}$ epoxy resin and polymerized for 24 $\mathrm{h}$ before being sectioned into $100 \mathrm{~nm}$ layers using a diamond knife with a Leica EM UC6 microtome, and subsequently the sections were mounted onto carbon grids. The observations via transmission electron microscopy (TEM) were performed using a JEOL 2011 at an accelerating voltage of $200 \mathrm{kV}$, which was used to study the HNT dispersion level within the polymer matrices. X-ray diffraction (XRD) measurements of prepared samples were performed in a Bruker Discover 8 X-ray diffractometer operated at $40 \mathrm{kV}$ and $40 \mathrm{~mA}$ using $\mathrm{Cu}-\mathrm{K}_{\alpha}$ radiation. The diffractometer was monochromatized with graphite-sample monochromators in a $2 \theta$ range from $5^{\circ}$ to $40^{\circ}$ with a scanning rate of $0.05^{\circ} / \mathrm{s}$. The $d$-spacing $(d)$ corresponding to the XRD peaks of HNT was determined from Bragg's law, $n \lambda=2 d \sin \theta$, where $\theta$ is the diffraction angle, $\lambda$ is the wavelength, which is $1.54 \AA$ for a $\mathrm{Cu}$ target, and $n$ is an integer. The degree of crystallinity was determined from XRD data in the range of $2 \theta$ from $10^{\circ}$ to $30^{\circ}$ by using the area integration method [15].

Thermal analysis was performed using a DSC6000 Perkin Elmer with Cryofill liquid nitrogen cooling system. Approximately $10 \mathrm{mg}$ of electrospun fiber mat was sealed in an aluminum pan. The thermal behavior was analyzed during the first heating scan between $30^{\circ} \mathrm{C}$ and $200^{\circ} \mathrm{C}$ with a ramp rate of $10^{\circ} \mathrm{C} / \mathrm{min}$ for as-received PLA pellets and PLA nanofibers; whereas PCL based materials were heated from -90 to $200^{\circ} \mathrm{C}$ at the same heating rate.

Fourier transform infrared spectroscopy (FTIR) was performed in a PerkinElmer Spectrum 100 FTIR Spectrometer. Spectra were recorded in the range of $4000-550 \mathrm{~cm}^{-1}$ 
with $4 \mathrm{~cm}^{-1}$ resolution by using an attenuated total reflectance (ATR) technique. FTIR was employed to investigate the interaction level between HNT and the biopolymers.

\section{Results and discussion}

\subsection{Effect of polymer concentration}

Blending PLA solution with two different concentrations of PCL solution (1:1 volume ratio) and chloroform/methanol solvents produced quite uniform electrospun fibrous structures with some variations of fiber diameters and morphology. Figure 1 shows that when increasing the PCL concentration from $9 \mathrm{wt} \% / \mathrm{v}$ to $15 \mathrm{wt} \% / \mathrm{v}$, the average diameter is enlarged accordingly from $689 \mathrm{~nm}$ to $814 \mathrm{~nm}$, as evidenced in Table 1. This finding is attributed to the increase in solution viscosity from $113 \mathrm{cP}$ for $9 \mathrm{wt} \% / \mathrm{v}$ PCL to $476 \mathrm{cP}$ for $15 \mathrm{wt} \% / \mathrm{v}$ PCL, Fig. 2, which is in good accordance with previous work, resulting in the production of large fiber diameters due to the higher solution viscosity $[16,17]$. The increase of solution viscosity is associated with an increase in the number of molecular entanglements per polymer chain and the lower amount of solvents present due to the increased solution concentration. The increase in viscosity is regarded as an important factor for the formation of a stable jet as it compensates for the increased surface tension [18].

\subsection{Effect of HNT}

Quite evidently, the addition of HNT tends to increase solution viscosity as expected, Fig. 2. Furthermore, the additional HNT often produced a uniform fibrous structure with large diameters as opposed to the corresponding PLA: PCL blends. The higher HNT level also led to larger fiber diameter irrespective of the PCL concentration, Figs. 3 and 4. Such increased diameters could be ascribed to the dominant effect of solution viscosity on the 
fiber morphological structure. This finding is contrary to the previous result [11], which reported that embedded HNT were associated with the production of small-diameter electrospun fibers due to the enhanced electrical conductivity of the solution.

Figure 4 demonstrates that the average fiber diameters of $15 \mathrm{wt} \% / \mathrm{v}$ PCL composites embedded with HNT-ASP remained nearly the same within the standard deviation for both 1 and $2 \mathrm{wt} \% / \mathrm{v}$ of HNT-ASP while there was a modest change in average diameters of the $9 \mathrm{wt} \% / \mathrm{v}$ PCL counterparts. The reason for this behavior might come from the almost unchanged viscosity of $15 \mathrm{wt} \% / \mathrm{v}$ PCL composites (538 and $540 \mathrm{cP}$ for 1 and 2 $\mathrm{wt} \% / \mathrm{v}$ of HNT-ASP, respectively). On the contrary, there was a moderate increase in average fiber diameters of 9 and $15 \mathrm{wt} \% / \mathrm{v}$ PCL composites owing to an increase of the viscosity when adding unmodified HNT, as illustrated in Fig. 2. This may be due to increased agglomeration of unmodified HNT, which in turn may lead to the increased viscosity. On the other hand, the average fiber diameters for $9 \mathrm{wt} \% / \mathrm{v}$ PCL when embedded with $1 \mathrm{wt} \% / \mathrm{v}$ unmodified HNT and HNT-ASP were unchanged within the standard deviation despite the noticeable difference in the viscosity, Fig. 2(a). The low viscosity for PCL $9 \mathrm{wt} \% / \mathrm{v}$ could prevent the formation of a HNT suspension and possibly cause HNT sedimentation compared to PCL $15 \mathrm{wt} \% / \mathrm{v}$. From Table 1 it can be seen that the difference in the average fiber diameters between composites embedded with unmodified HNT and modified HNT-ASP increases with increasing HNT concentration from 1 to $2 \mathrm{wt} \% / \mathrm{v}$, which may be explained by the enhanced agglomeration behavior caused by increasing the amount of HNT used. 


\subsection{TEM results}

Figure 5(a) shows the TEM images of composites embedded with unmodified HNT. It can be seen that many HNT particles are clearly formed with agglomerates. The HNT have become aggregated as a result of strong hydrogen bonding between the filler particles [19]. Despite the existence of some degree of agglomeration, the TEM image in Fig. 5(b) shows that HNT-ASP are individually better dispersed into the PLA: PCL blend and epoxy matrices in this composite system as compared to that without ASP, Fig. 5(a). As observed in Fig. 5(a), PLA: PCL-rich fibrous structures are produced, which are separate from the HNT and form their own individual skewed fiber clusters. This phenomenon is not noticeable in Fig. 5(b) for HNT-ASP, which suggests that good interactions might take place between PLA: PCL fibers and HNT, and some of PLA: PCL fibers easily penetrate into the hollow structures of HNT. It appears that the ASP could promote the HNT dispersion level to a certain extent. This is because the ASP reacts with the HNT surface during the particle interactions, which thus helps in turn to reduce the adhesion between the modified HNT. The non-homogenous orientations of HNT and PLA: PCL fibers, as clearly shown in Fig. 5, could be explained by two plausible reasons. First, the electrospinning process used in this study may have less control of the tailored fibers, allowing them to be entangled when collected on the mesh collector. Second, the polymerization of electrospun fibers and epoxy resin has little influence on the preferred orientation, which is in contrast to the injection molding, generally used in processing polymer/clay nanocomposites. Due to such random orientation, the TEM images could show both the cross-sectional and lateral views of HNT, as evidenced from the black circular dots or tubes, respectively, in Fig. 5(b). 


\subsection{Crystallinity and thermal properties}

An XRD investigation was carried out to explore the changes in crystallinity due to the PCL concentration, and HNT and HNT-ASP structures, on the electrospun composites produced. Fig. 6 shows the XRD patterns for blending PLA with two concentrations of PCL, $9 \mathrm{wt} \% / \mathrm{v}$ and $15 \mathrm{wt} \% / \mathrm{v}$. It can be seen that when the PLA and PCL blends contained a higher PCL concentration, the diffraction peaks of PLA: PCL at angles of $2 \theta=20.11^{\circ}$ and $23.2^{\circ}$, corresponding to the planes (101) and (200), respectively, become more prominent due to the positive contribution of PCL to the crystallization level of the blends. It is evident from Fig. 7 that the degree of crystallinity $\left(X_{c}\right)$ obtained from XRD patterns was also enhanced in PLA: 15\% PCL as opposed to PLA: 9\% PCL due to the addition of PCL with moderate crystallinity in place of amorphous phase PLA with low crystallinity.

Figure 6 shows the XRD reflections of as-received HNT, with the crystal planes $(h k l)$ corresponding to the main crystalline peaks and $d$-spacing as obtained from the DICVOL program in the FullProf software package [20]. Their characteristic XRD peak was detected at $2 \theta=12.44^{\circ}$, which corresponds to the reflection plane of (001), with $d$ spacing value of $0.72 \mathrm{~nm}$. This HNT basal reflection results from its tubular morphology and small crystal size $(L)$ of $21.71 \mathrm{~nm}$ that was calculated from the Scherrer relation [21]. The diffraction pattern of HNT also shows other peaks at $2 \theta=20.21^{\circ}$ and $24.94^{\circ}$, corresponding to the (110) and (002) reflection planes with $d$-spacing values of 0.44 and $0.36 \mathrm{~nm}$, respectively. Furthermore, based on the database of the EVA program (Bruker AXS, Inc., USA), it has been found that HNT used in this study is referred to as (7 $\AA$ )halloysite with a dehydrated formation [22], since the peak at about $2 \theta=8.76^{\circ}$ for hydrated particles completely disappears. Figure 6 also shows the XRD patterns for PLA: 
15\% PCL composites embedded with $1 \mathrm{wt} \% / \mathrm{v}$ HNT and HNT-ASP. The XRD peaks for HNT-ASP based composites are displayed at $2 \theta=12.21^{\circ}, 19.87^{\circ}$, and $23.26^{\circ}$ with $d$ spacing values of $0.73,0.45$ and $0.39 \mathrm{~nm}$ corresponding to the planes (001), (102), and (111), respectively. The (001) peaks of unmodified HNT and HNT-ASP based nanocomposites were shorter and broader compared with that of as-received HNT powders, which might imply the break-up of large HNT agglomerates into sub-micron particles. Additionally, the (001) peaks were slightly shifted to lower angles of $12.35^{\circ}$ and $12.21^{\circ}$ for HNT and HNT-ASP based composites relative to that of as-received HNT at $2 \theta=12.44^{\circ}$. This phenomenon suggests that HNT-ASP shows slightly better dispersion than unmodified HNT in good accordance with the TEM result in Fig. 5(b). A possible reason could be that the agglomeration tendency decreases when using HNT-ASP, which might assist the HNT dispersion in the polymer matrix with reduced aggregates. The first peak (001) intensities have decreased for unmodified HNT and HNT-ASP based composites when compared to that of as-received HNT, further implying the less wellordered formation of HNT particles. As also confirmed from TEM results in Fig. 5, it is believed that HNT become partly disordered and randomly oriented.

It can be noted from Fig. 7 that the addition of $1 \mathrm{wt} \% / \mathrm{v}$ HNT decreased the crystallinity of composites as opposed to that of PLA: 15\% PCL because the resulting degree of crystallinity is influenced by the restricted mobility of the polymer chains, which prevents good growth of the crystals. This new material system with moderate crystallinity might be a good candidate for steady drug release since PCL with high crystallinity tends to push the drug to the fiber surfaces [13] while PLA with low 
crystallinity can accelerate the fiber degradability, thus possibly resulting in the faster process of drug release in both cases.

The thermal behavior of electrospun composites was also evaluated in the present work. Data are presented for the first heating scan only. The data for cooling scans were neglected because during the cooling scan no heat flow peak was observed owing to the cold crystallization nature of PLA [23]. The DSC results in Fig. 8 and Table 2 show that the crystallization temperature $\left(T_{c}\right)$ of as-received PLA was higher than the $T_{c}$ of PLA fibers because the crystallization process can be accelerated by the well-structured PLA molecular chains in the fiber-like form. The glass transition temperature $\left(T_{g}\right)$ of PCL within the PLA: PCL blends becomes higher when the PCL concentration increases from 9 to $15 \mathrm{wt} \% / \mathrm{v}$. However, the $T_{g}$ of PLA within the blends is hardly detectable because its transitional region in DSC curves overlaps the melting peak of PCL, Fig. 8. Additionally, the use of HNT-ASP in the composites led to moderate decreases in the values of $T_{g}$ of PCL and $T_{c}$ of PLA, but demonstrates a more pronounced decreasing tendency relative to those with unmodified HNT. The nucleating agent role of HNT has been shown to promote the heterogeneous nucleation of polymeric molecules, as evidenced by the decrease of $T_{c}$, especially in PLA: 15\% PCL composites embedded with $1 \mathrm{wt} \% / \mathrm{v}$ HNTASP as compared to PLA: 15\% PCL blends.

The slight decrease of $T_{g}$ in PCL of HNT-ASP based composites results from the decreased crystallinity and better HNT dispersion corroborated by the aforementioned XRD results when compared to that of the unmodified HNT based counterparts. The variations of $T_{m}$ and $T_{g}$ values could be attributed to the electrospinning process 
conditions and resulting dispersed fiber diameters, which influence the orientation of the polymeric chains [24].

\subsection{FTIR examination}

The change of compositions was investigated by Fourier Transform Infrared Spectroscopy (FTIR). Figure 9 shows that PLA: PCL electrospun fibers displayed initially two carbonyl stretching $(\mathrm{C}=\mathrm{O})$ bands at $1724 \mathrm{~cm}^{-1}$ for $\mathrm{PCL}$ and at $1757 \mathrm{~cm}^{-1}$ for PLA. The spectrum of HNT exhibits two intense bands at $3621 \mathrm{~cm}^{-1}$ and $3694 \mathrm{~cm}^{-1}$, which are assigned to the $\mathrm{O}-\mathrm{H}$ group vibration. The peaks at $1117 \mathrm{~cm}^{-1}, 1027 \mathrm{~cm}^{-1}$, and $1005 \mathrm{~cm}^{-1}$ are associated with stretching of $\mathrm{Si}-\mathrm{O}$, and the adsorption peak at $910 \mathrm{~cm}^{-1}$ is assigned to Al-OH groups. The internal surface of HNT is composed of aluminol (Al$\mathrm{OH})$ groups whilst the external surface consists of siloxane $(\mathrm{Si}-\mathrm{O})$ groups. The modification between ASP and HNT happens by joining molecules of hydrolyzed ASP directly to the surface hydroxyl group factions of HNT, which include the aluminol and silanol groups at HNT tube edge and the aluminol groups at their internal lumen surface.

A comparison of the spectra in Fig. 9 shows the phenomenon that FTIR peaks have been either shifted, appeared or completely disappeared. The single PLA: PCL band at $1184 \mathrm{~cm}^{-1}$ has been broadened and shifted to lower wave numbers of 1167 and $1179 \mathrm{~cm}^{-1}$, when incorporating HNT and HNT-ASP into the PLA: PCL blends, respectively. It suggested that a moderate contribution of the HNT bands with wave numbers of 1117 , 1027 , and $1005 \mathrm{~cm}^{-1}$ is associated with the stretching of $\mathrm{Si}-\mathrm{O}$. Furthermore, the peak of the PLA: PCL composites embedded with unmodified HNT disappeared at $1130 \mathrm{~cm}^{-1}$, while at $913 \mathrm{~cm}^{-1}$ a new peak occurred for PLA: PCL composites embedded with HNTASP. It could be due to the HNT bond detected at $910 \mathrm{~cm}^{-1}$, which is assigned to the Al- 
OH groups. In addition, vibration bands at 3622 and $3695 \mathrm{~cm}^{-1}$, in the presence of the surface hydroxyl groups and the $\mathrm{O}-\mathrm{H}$ group, also confirm the successful embedding characteristic of HNT-ASP within PLA: PCL blends in the infrared spectra of final composites, thus corroborating the previously obtained TEM and XRD results.

\section{Conclusions}

This investigation focused on the structure and morphological properties of electrospun composites produced by blending two different concentrations of PCL solution with a PLA solution at a 1:1 volume ratio using chloroform/methanol solvents. The PLA: PCL blends were embedded with two different concentrations ( $1 \mathrm{wt} \% / \mathrm{v}$ and 2 wt $\% / v)$ of HNT, and both unmodified HNT and modified HNT-ASP were investigated. Increasing the PCL concentration to $15 \mathrm{wt} \% / \mathrm{v}$ increased the average fiber diameter compared with $9 \mathrm{wt} \% / \mathrm{v}$ PCL, and this effect was attributed to the increase in solution viscosity. Furthermore, the addition of HNT, with and without the ASP, also tends to cause a further increase of the solution viscosity, resulting in a uniform fiber structure with larger diameters compared to PLA: PCL blends. By using PCL $15 \mathrm{wt} \% / \mathrm{v}$, the average fiber diameters for the composite with HNT-ASP decreased noticeably compared with those with unmodified HNT and their difference in the average fiber diameters has increased with increasing HNT concentration from 1 to $2 \mathrm{wt} \% / \mathrm{v}$. HNT-ASP dispersion was slightly improved relative to unmodified HNT within the composites. The $T_{c}$ of asreceived PLA was higher than that of PLA fibers. The increased PCL concentration within PLA: PCL blends led to an increase in both the $T_{g}$ value and crystallinity level of PCL. The values of $T_{c}, T_{g}$ and $T_{m}$ slightly decreased when HNT were used within the polymer blend, the extent of which was relatively high for HNT-ASP inclusions. A 
successful embedding of HNT-ASP into PLA: PCL blends, compared with unmodified HNT, was confirmed by the infrared spectra.

\section{Acknowledgements}

The PhD scholarship awarded by the Iraqi government to Mr. Hazim J. Haroosh and the financial support of Curtin Internal Research Grants (IRG) 2010 (Project No. 47604) to Dr. Yu Dong are gratefully acknowledged. The authors also wish to thank the Curtin Electron Microscopy lab and Applied Physics lab for technical assistance with SEM and XRD analyses, respectively.

\section{References}

[1] S. Heydarkhan-Hagvall, K. Schenke-Layland, A. Dhanasopon, F. Rofail, H. Smith, B. Wu, R. Shemin, R. Beygui, and W. MacLellan, Biomaterials 29, 2907 (2008).

[2] Q. Pham, U. Sharma, and A. Mikos, Tissue engineering 12, 1197 (2006).

[3] D. Liang, B. Hsiao, and B. Chu, Advanced drug delivery reviews 59, 1392 (2007).

[4] H. Jiang, Y. Hu, P. Zhao, Y. Li, and K. Zhu, Journal of Biomedical Materials Research Part B: Applied Biomaterials 79, 50 (2006).

[5] D. Yang, Y. Li, and J. Nie, Carbohydrate Polymers 69, 538 (2007).

[6] Y. Ji, K. Ghosh, X. Shu, B. Li, J. Sokolov, G. Prestwich, R. Clark, and M. Rafailovich, Biomaterials 27, 3782 (2006).

[7] J. Han, C. Branford-White, and L. Zhu, Carbohydrate Polymers 79, 214 (2010).

[8] G. Kim, H. Yoon, and Y. Park, Applied Physics A: Materials Science \& Processing, 100, 1197 (2010).

[9] K. Kim, M. Yu, X. Zong, J. Chiu, D. Fang, Y. Seo, B. Hsiao, B. Chu, and M. Hadjiargyrou, Biomaterials 24, 4977 (2003).

[10] W. Cui, X. Li, X. Zhu, G. Yu, S. Zhou, and J. Weng, Biomacromolecules 7, 1623 (2006).

[11] M. Liu, B. Guo, M. Du, F. Chen, and D. Jia, Polymer 50, 3022 (2009). 
[12] A. Touny, J. Lawrence, A. Jones, and S. Bhaduri, Journal of Materials Research 25, 857 (2010).

[13]E. Kenawy, G. Bowlin, K. Mansfield, J. Layman, D. Simpson, E. Sanders, and G. Wnek, Journal of Controlled Release 81, 57 (2002).

[14] P. Haque, I. Barker, A. Parsons, K. Thurecht, I. Ahmed, G. Walker, C. Rudd, and D. Irvine, Journal of Polymer Science Part A: Polymer Chemistry 48, 3082 (2010).

[15]L. E. Alexander, X-ray diffraction methods in polymer science (Wiley-Interscience New York, 1969).

[16]M. Zamani, M. Morshed, J. Varshosaz, and M. Jannesari, European Journal of Pharmaceutics and Biopharmaceutics 75, 179 (2010).

[17] K. Arayanarakul, N. Choktaweesap, D. Aht ong, C. Meechaisue, and P. Supaphol, Macromolecular Materials and Engineering 291, 581 (2006).

[18] M. Spasova, O. Stoilova, N. Manolova, I. Rashkov, and G. Altankov, Journal of Bioactive and Compatible Polymers 22, 62 (2007).

[19]M. Liu, B. Guo, M. Du, and D. Jia, Applied Physics A: Materials Science \& Processing 88, 391 (2007).

[20] A. Boultif and D. Louer, Journal of applied crystallography 37, 724 (2004).

[21] N. Ning, Q. Yin, F. Luo, Q. Zhang, R. Du, and Q. Fu, Polymer 48, 7374 (2007).

[22]Y. Dong, D. Chaudhary, H. Haroosh, and T. Bickford, Journal of materials science 46, 6148 (2011).

[23] M. Shibata, Y. Inoue, and M. Miyoshi, Polymer 47, 3557 (2006).

[24]P. Picciani, E. Medeiros, Z. Pan, D. Wood, W. Orts, L. Mattoso, and B. Soares, Macromolecular Materials and Engineering 295, 618 (2010). 


\section{$\underline{\text { Figure Captions }}$}

Fig. 1 SEM micrographs of electrospun $8 \mathrm{wt} \% / \mathrm{v}$ PLA solution with (a) $9 \mathrm{wt} \% / \mathrm{v}$ PCL solution, and (b) $15 \mathrm{wt} \% / \mathrm{v}$ PCL solution.

Fig. 2 Solution viscosity of PLA: PCL composites with unmodified HNT and HNT-ASP: (a) $9 \mathrm{wt} \% / \mathrm{v}$ PCL, and (b) $15 \mathrm{wt} \% / \mathrm{v}$ PCL.

Fig. 3 SEM micrographs of electrospun PLA: PCL composites with unmodified HNT: (a) $9 \mathrm{wt} \% / \mathrm{v}$ PCL with $1 \mathrm{wt} \% / \mathrm{v} \mathrm{HNT}$, (b) $9 \mathrm{wt} \% / \mathrm{v}$ PCL with $2 \mathrm{wt} \% / \mathrm{v}$ HNT, (c) $15 \mathrm{wt} \% / \mathrm{v}$ PCL with $1 \mathrm{wt} \% / \mathrm{v}$ HNT, and (d) $15 \mathrm{wt} \% / \mathrm{v}$ PCL with $2 \mathrm{wt} \% / \mathrm{v}$ HNT.

Fig. 4 SEM micrographs of electrospun PLA:PCL composites with HNT-ASP: (a) 9 wt $\% / v$ PCL with $1 \mathrm{wt} \% / \mathrm{v}$ HNT-ASP, (b) $9 \mathrm{wt} \% / \mathrm{v}$ PCL with $2 \mathrm{wt} \% / \mathrm{v}$ HNT-ASP, (c) 15 wt $\% / v$ PCL with $1 \mathrm{wt} \% / \mathrm{v}$ HNT-ASP, and (d) $15 \mathrm{wt} \% / \mathrm{v}$ PCL with $2 \mathrm{wt} \% / \mathrm{v}$ HNT-ASP.

Fig. 5 TEM images of PLA: 15\% PCL composites embedded with (a) unmodified HNT, and (b) HNT-ASP.

Fig. $6 \mathrm{X}$-ray diffraction patterns for selected samples showing the relative positions of the reflection peaks due to the effect of HNT and HNT-ASP in PLA: PCL composites with different concentrations of PCL ( $9 \mathrm{wt} \% / \mathrm{v}$ and $15 \mathrm{wt} \% / \mathrm{v})$.

Fig. 7 Degree of crystallinity $\left(X_{c}\right)$ results for PLA, PCL and PLA: PCL composites embedded with HNT and HNT-ASP (calculated from XRD data).

Fig. 8 DSC thermograms for selected samples including as-received PLA, electrospun PLA and PCL fibers, PLA: 9\% PCL fibers, PLA: 15\% PCL fibers, PLA: 15\% PCL composites with $1 \%$ HNT and $1 \%$ HNT-ASP.

Fig. 9 FTIR spectra for selected samples including as-received HNT, electrospun PLA: $15 \%$ PCL fibers, and PLA: $15 \%$ PCL composites with $1 \%$ HNT and $1 \%$ HNT-ASP. 
Table 1 Average fiber diameters (nm) for PLA: PCL and PLA:PCL composites: effect of HNT type and concentration.

\begin{tabular}{|c|c|c|c|c|c|c|}
\hline & \multicolumn{2}{|c|}{$9 \mathrm{wt} \% / \mathrm{v}$ PCL } & \multicolumn{2}{c|}{$15 \mathrm{wt} \% / \mathrm{v}$ PCL } & $\begin{array}{c}9 \mathrm{wt} \% / \mathrm{v} \\
\text { PCL }\end{array}$ & $\begin{array}{c}15 \mathrm{wt} \% / \mathrm{v} \\
\text { PCL }\end{array}$ \\
\hline & $\begin{array}{c}1 \mathrm{wt} \% / \mathrm{v} \\
\mathrm{HNT}\end{array}$ & $\begin{array}{c}2 \mathrm{wt} \% / \mathrm{v} \\
\mathrm{HNT}\end{array}$ & $\begin{array}{c}1 \mathrm{wt} \% / \mathrm{v} \\
\mathrm{HNT}\end{array}$ & $\begin{array}{c}2 \mathrm{wt} \% / \mathrm{v} \\
\mathrm{HNT}\end{array}$ & $\begin{array}{c}0 \mathrm{wt} \% / \mathrm{v} \\
\mathrm{HNT}\end{array}$ & $\begin{array}{c}0 \mathrm{wt} \% / \mathrm{v} \\
\mathrm{HNT}\end{array}$ \\
\cline { 5 - 7 } & & & & & $\begin{array}{c}689 \\
( \pm 15)\end{array}$ & $\begin{array}{c}814 \\
( \pm 15)\end{array}$ \\
\hline Unmodified & 726 & 981 & 1087 & 1233 & & \\
HNT & $( \pm 20)$ & $( \pm 20)$ & $( \pm 20)$ & $( \pm 25)$ & & \\
\hline HNT modified & 703 & 812 & 905 & 927 & & \\
with ASP & $( \pm 15)$ & $( \pm 15)$ & $( \pm 25)$ & $( \pm 25)$ & & \\
\hline
\end{tabular}


Table 2 DSC results for PLA, PCL and PLA: PCL composites embedded with unmodified HNT and modified HNT-ASP.

\begin{tabular}{|l|l|l|l|l|l|l|}
\hline Material sample & $\begin{array}{l}T_{g}\left({ }^{\circ} \mathrm{C}\right) \\
\mathrm{PCL}\end{array}$ & $\begin{array}{l}T_{m}\left({ }^{\circ} \mathrm{C}\right) \\
\mathrm{PCL}\end{array}$ & $\begin{array}{l}T_{g}\left({ }^{\circ} \mathrm{C}\right) \\
\text { PLA }\end{array}$ & $\begin{array}{l}T_{c}\left({ }^{\circ} \mathrm{C}\right) \\
\text { PLA }\end{array}$ & $\begin{array}{l}T_{m}\left({ }^{\circ} \mathrm{C}\right) \\
\text { PLA }\end{array}$ & $\begin{array}{l}\Delta H_{m}(\mathrm{~J} / \mathrm{g}) \\
\text { PLA }\end{array}$ \\
\hline PLA (As-received) & - & - & 65.21 & 120.64 & 152.58 & 22.56 \\
\hline PLA (Fibers) & - & - & 64.13 & 87.17 & 155.62 & 21.07 \\
\hline PCL (Fibers) & -58.04 & 63.10 & - & - & - & - \\
\hline PLA : 9\% PCL & -56.15 & 62.20 & - & 81.13 & 151.59 & 11.25 \\
\hline PLA : 15\% PCL & -52.19 & 63.75 & - & 83.97 & 152.54 & 7.53 \\
\hline PLA : $15 \%$ PCL(1\% HNT) & -56.48 & 63.40 & - & 83.06 & 152.38 & 3.12 \\
\hline PLA : $15 \%$ PCL(1\% HNT-ASP) & -58.34 & 62.84 & - & 81.10 & 151.05 & 6.24 \\
\hline
\end{tabular}

Note: Calculations were repeated for three sets of samples. The standard deviation for the $T_{c}, T_{g}$ and $T_{m}$ values was less than $0.5 \%$. 


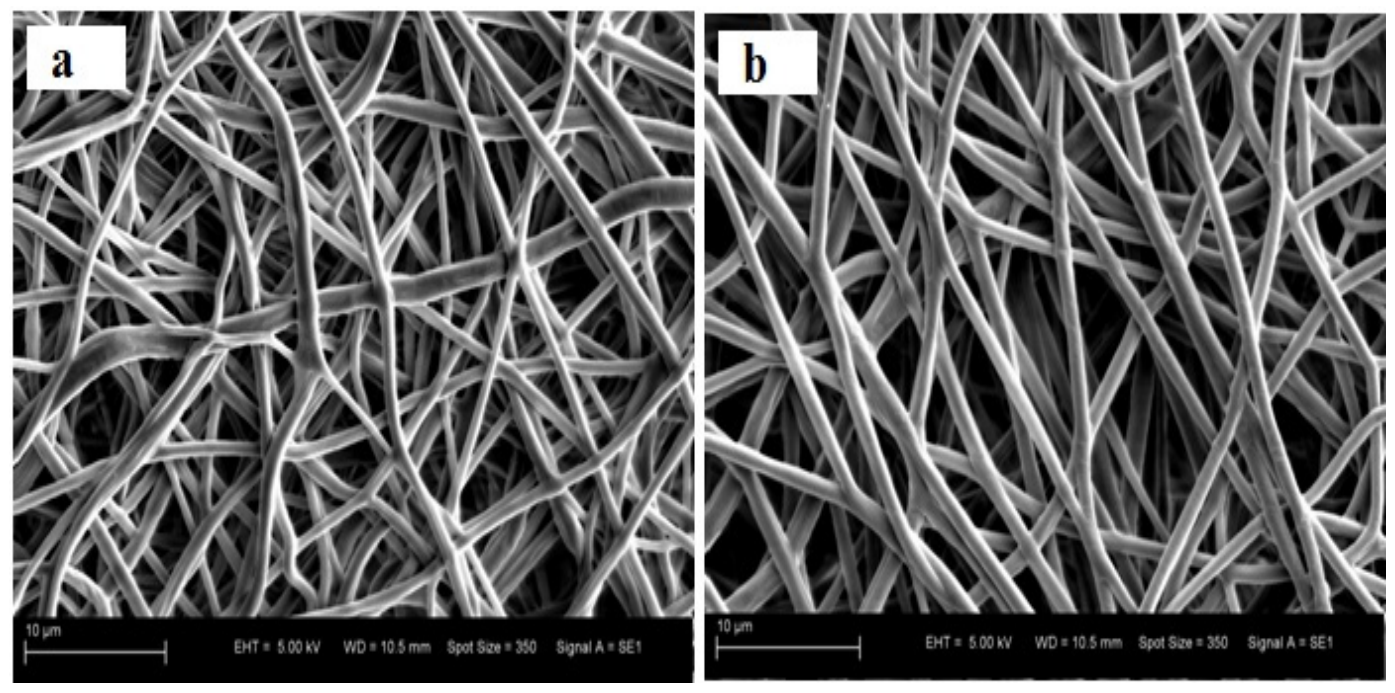

Fig. 1 


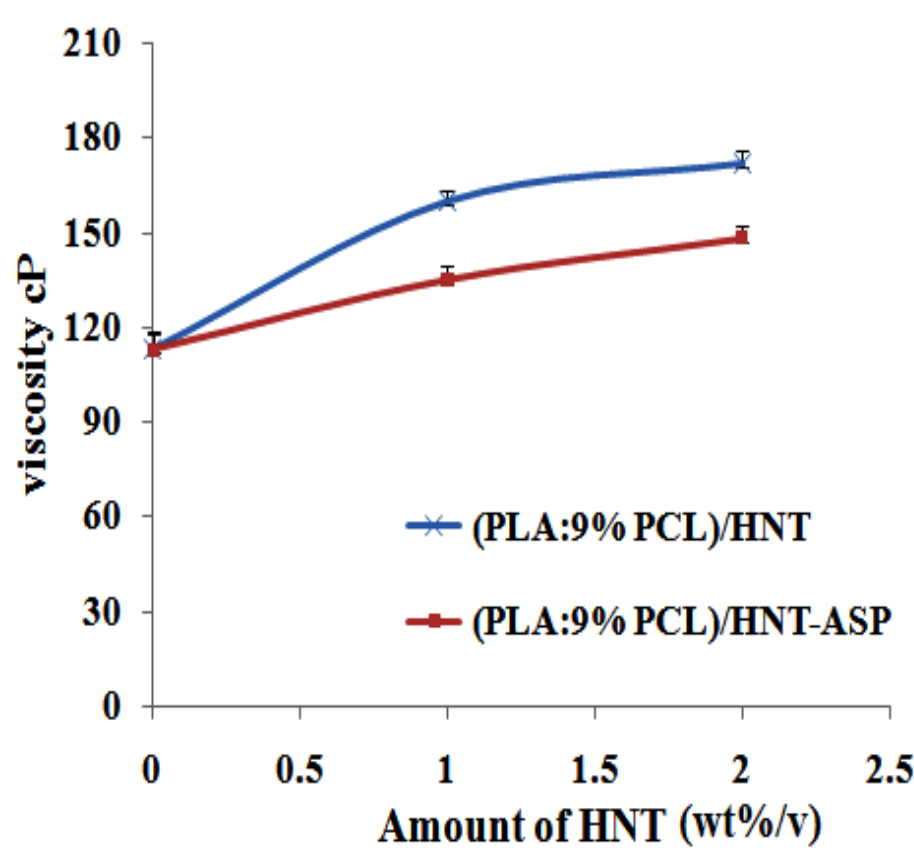

(a)

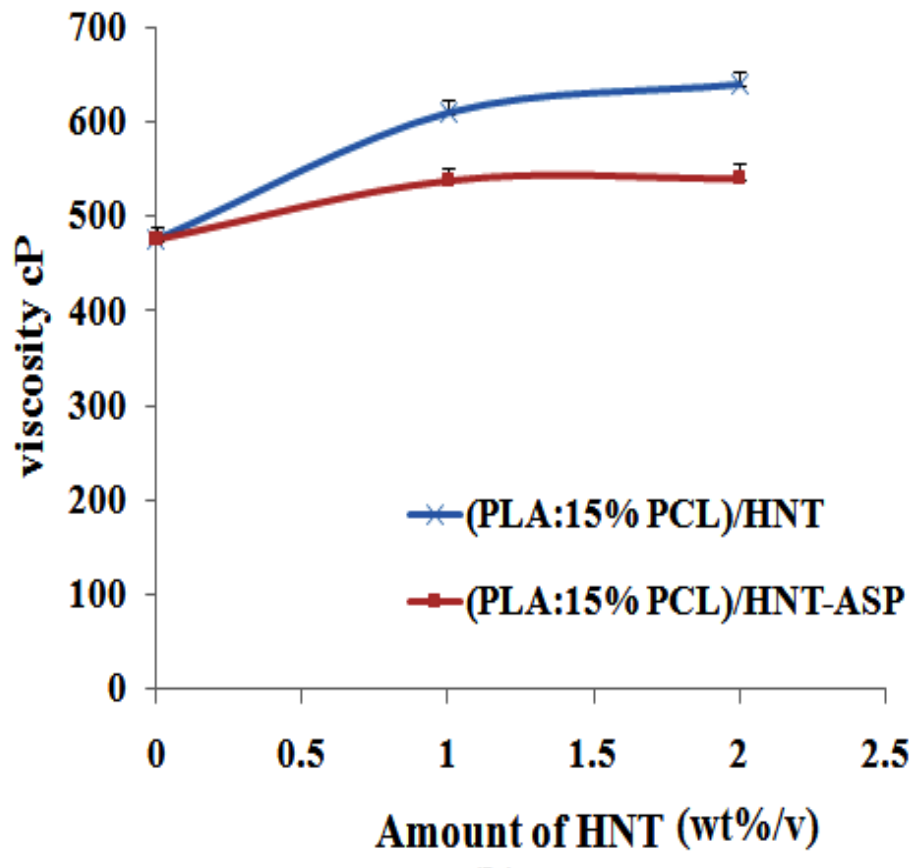

(b)

Fig. 2 

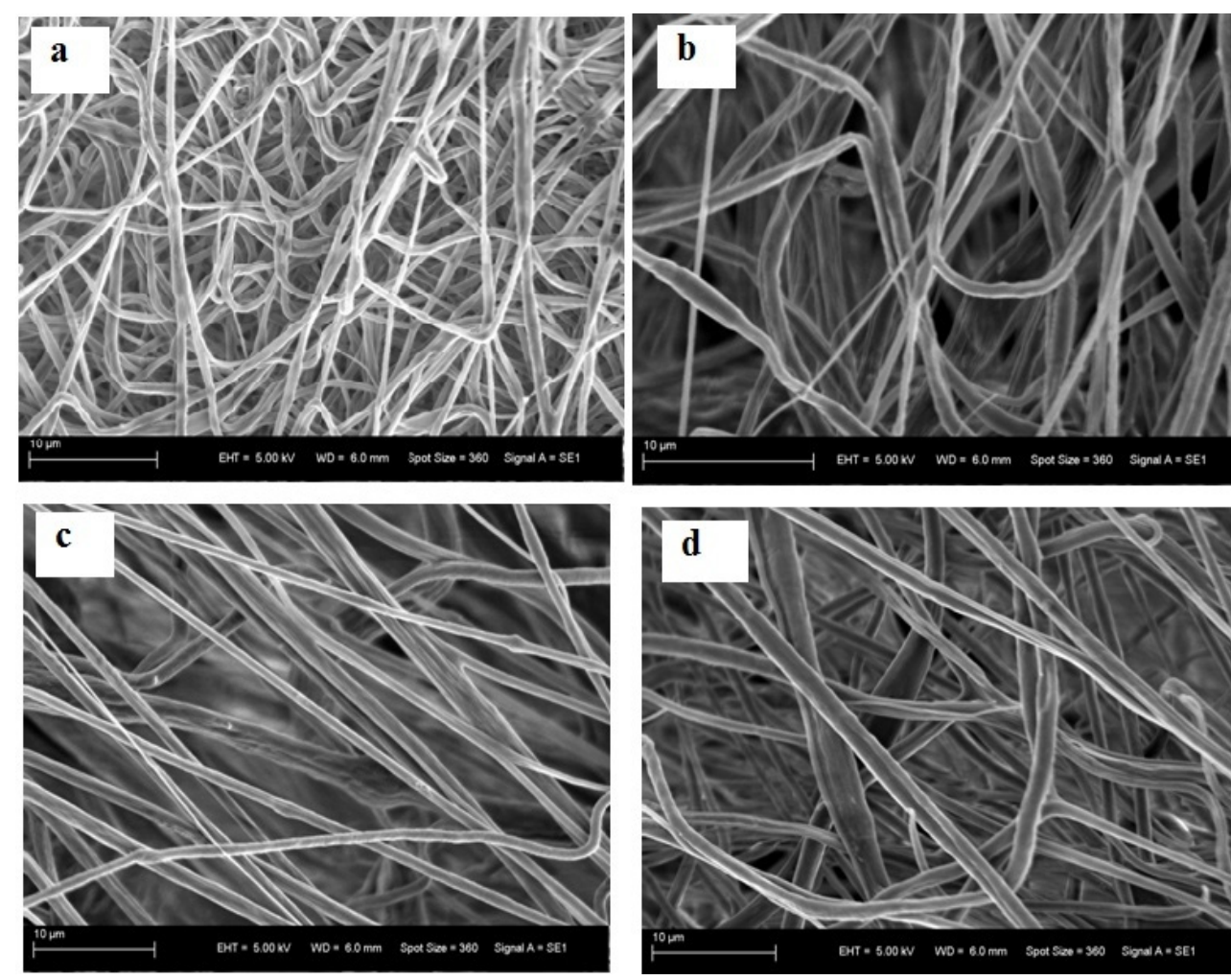

Fig. 3 

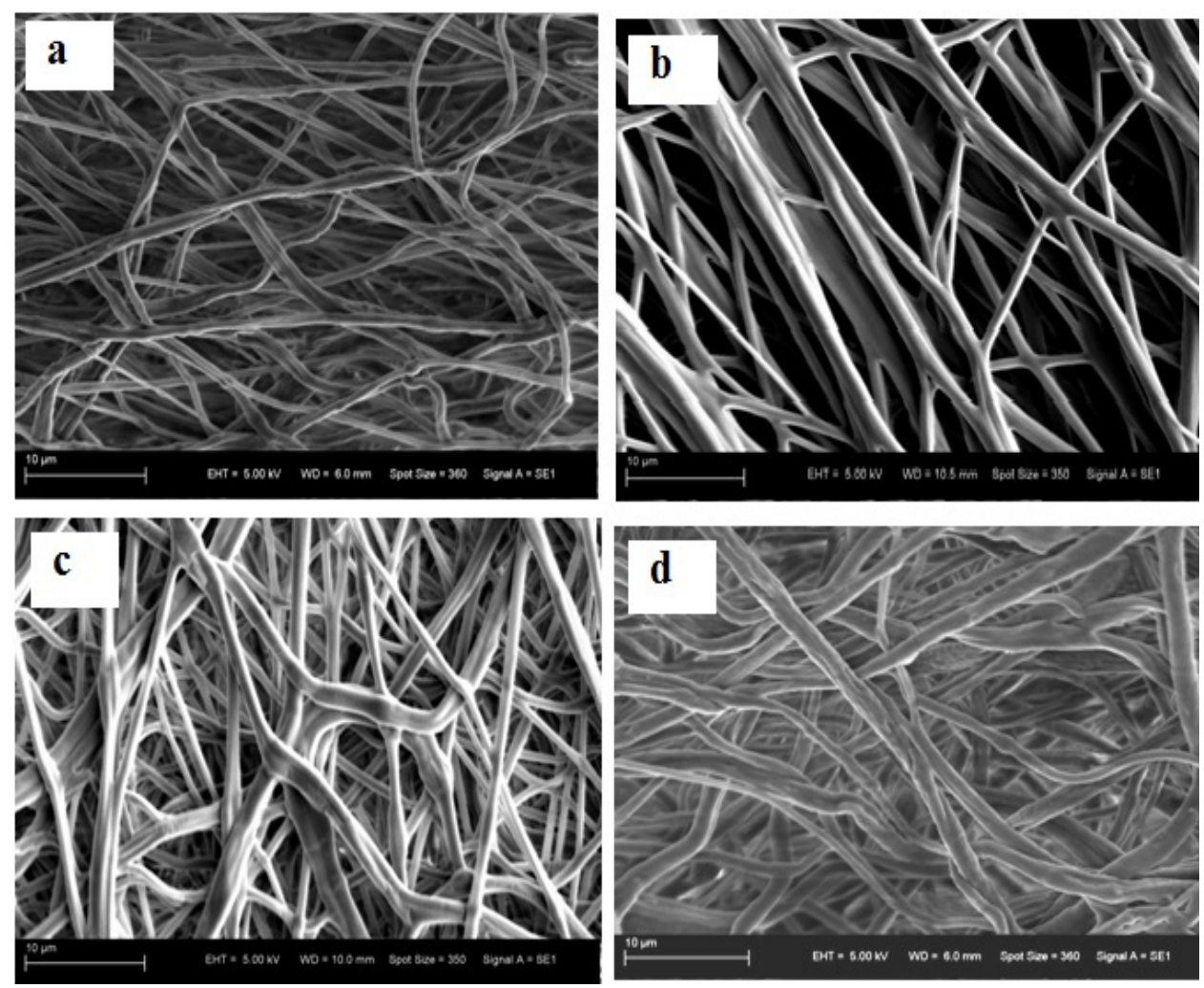

Fig. 4 

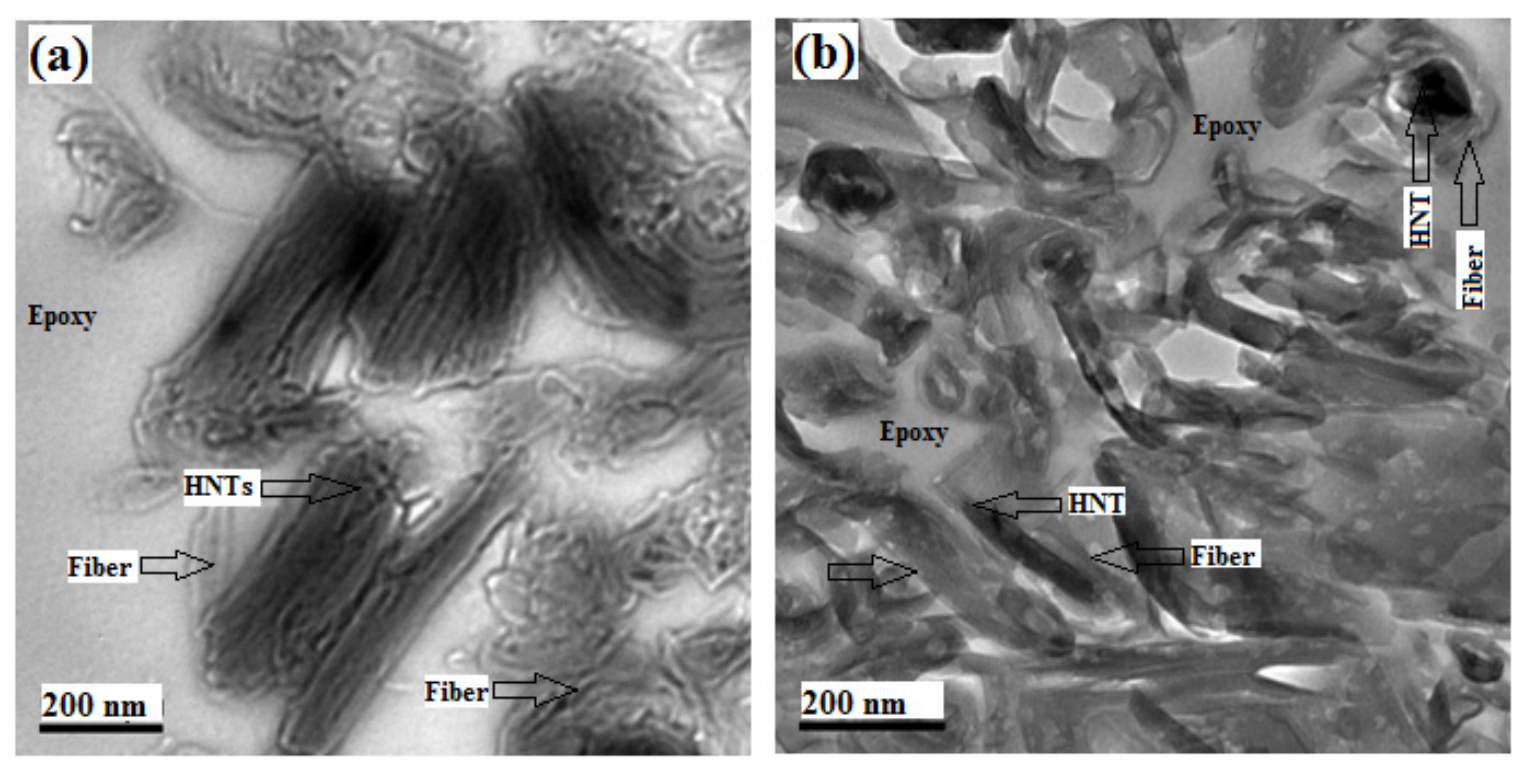

Fig. 5 


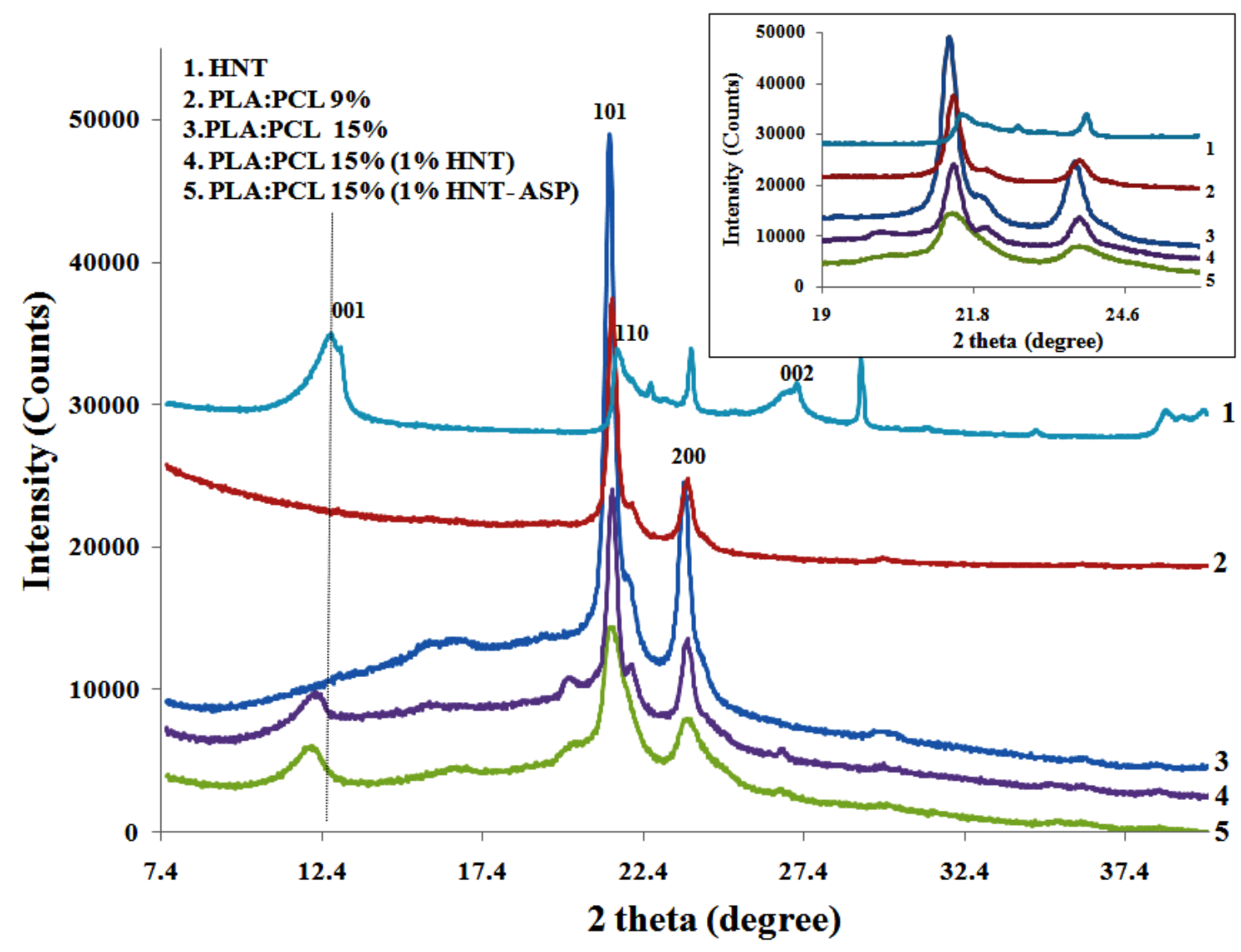

Fig. 6 


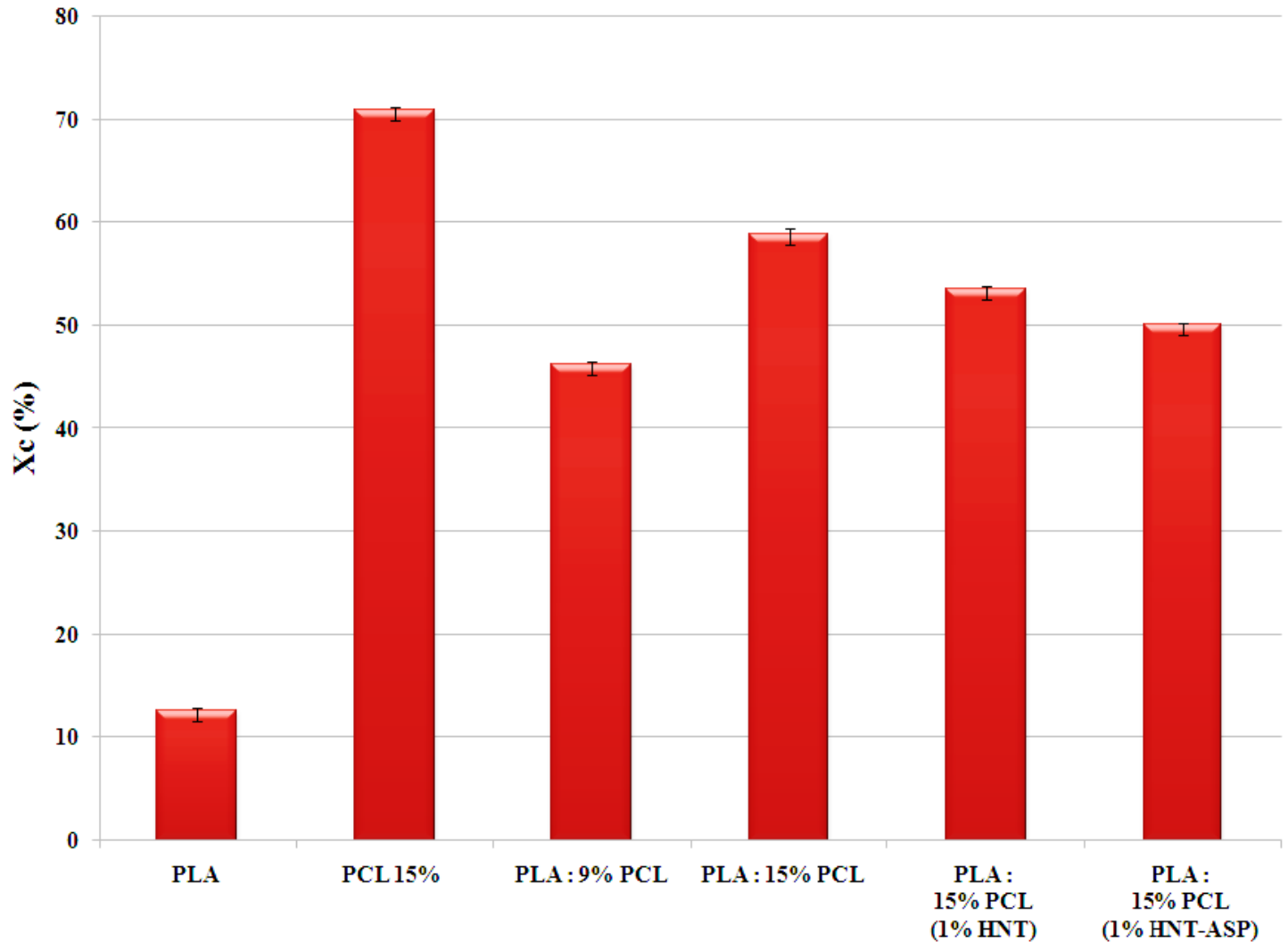

Fig. 7 


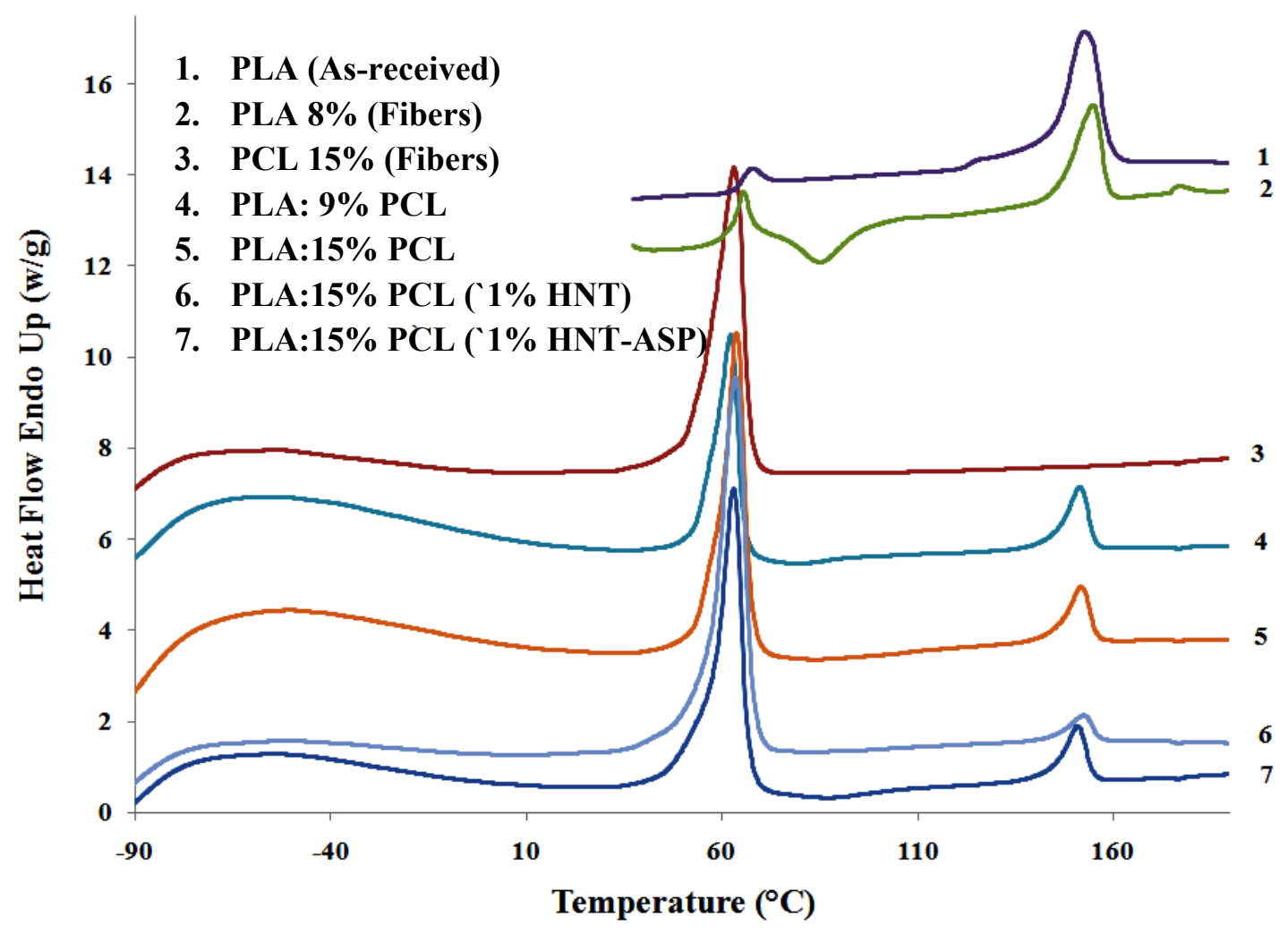

Fig. 8 


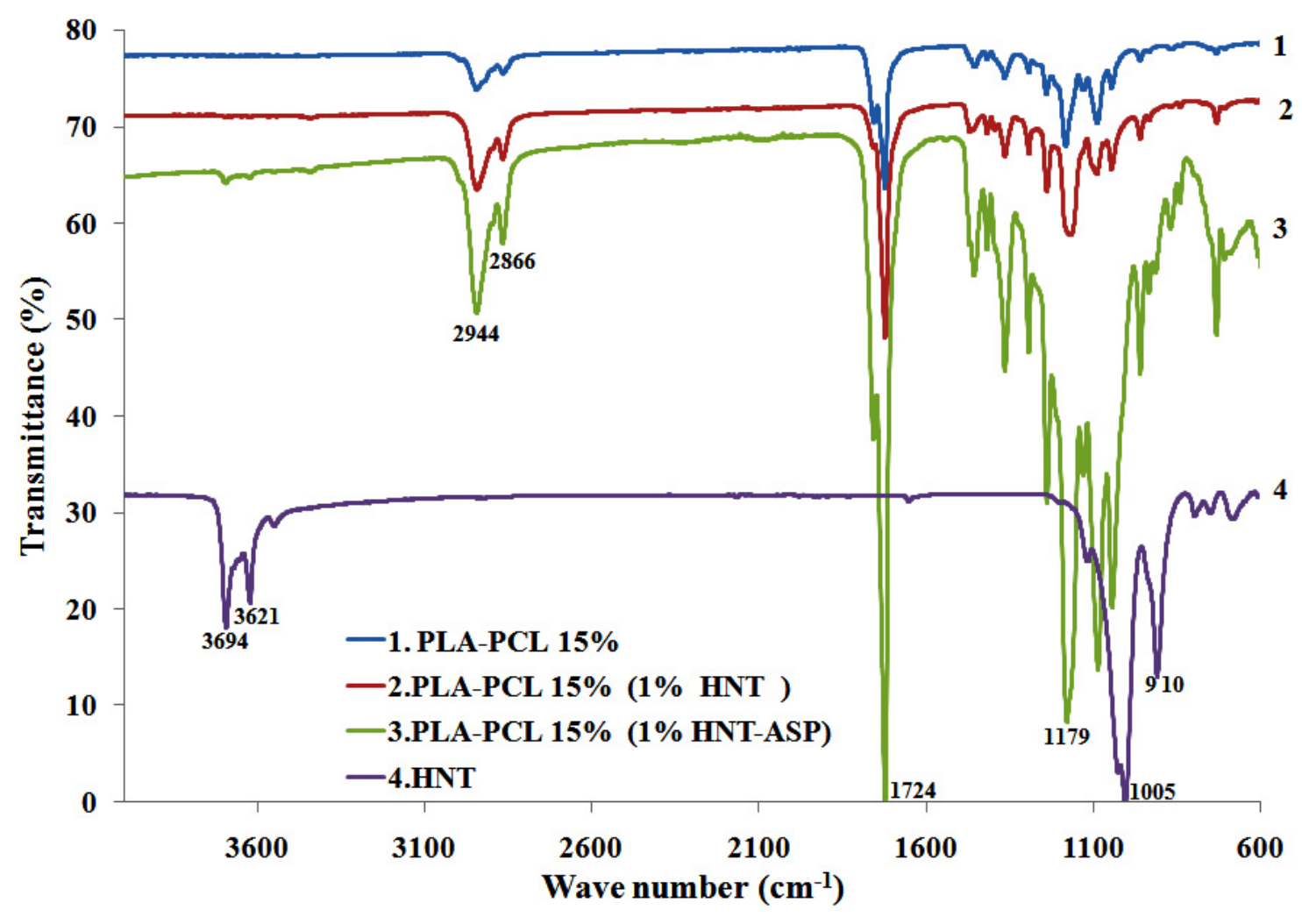

Fig. 9 